\title{
THERMOGRAVIMETRIC ANALYSIS OF INDICATORS OF THE PASTE BASED ON SOUR CREAM
}

\author{
Oksana Kochubei-Lytvynenko \\ Director \\ Educational and Scientific Institute of Food Technologies \\ National University of Food Technologies \\ 68 Volodymyrska str., Kyiv, Ukraine, 01601 \\ okolit@email.ua \\ Andrii Marynin \\ Laboratory of Problem research \\ National University of Food Technologies \\ 68 Volodymyrska str., Kyiv, Ukraine, 01601 \\ andrii_marynin@ukr.net \\ Natalya Yushchenko \\ Department of Milk and Dairy Product Technology \\ National University of Food Technologies \\ 68 Volodymyrska str., Kyiv, Ukraine, 01601 \\ YuNM_NUFT@ukr.net \\ Ulyana Kuzmyk \\ Department of Milk and Dairy Product Technology \\ National University of Food Technologies \\ 68 Volodymyrska str., Kyiv, Ukraine, 01601 \\ ukuzmik@gmail.com \\ Maxim Lazarenko \\ Department of Molecular Physics \\ Kyiv National University Taras Shevchenko \\ 64/13 Volodymyrska str., Kyiv, Ukraine, 01601 \\ maxs@univ.kiev.ua
}

\footnotetext{
Abstract

For forming structural-mechanical properties of sour milk pastes and guaranteeing their stability at storage, it is promising to use non-fried buckwheat in their recipes that allows to raise the food value of products additionally.

The aim of the researches was the study of features of the condition of moisture of sour milk pastes, based on sour cream with introducing non-fried buckwheat in the amount 5,0\% of the mixture mass. A sample with modified starch E 1410 was taken as a control in the amount $1,3 \%$.

The study of the moisture condition was realized by the thermogravimetric method using a derivatograph Q-1500D (Paulik-Erdey) (Hungry). It was established, that the content of adsorptive moisture of the sour milk paste was $34,0 \%$, whereas in the control $-34,5 \%$, that confirm the effectiveness of using non-fried buckwheat as a moisture-binding component. Such properties of non-fried buckwheat may be explained by the presence of starch compounds and easily accessible protein in its composition, able to hydration in the process of preparation of a component and to keeping moisture at further storage of a product.

Keywords: moisture condition, non-fried buckwheat, thermogravimetric analysis, moisture-binding properties, sour milk pastes, sour cream. 


\section{Introduction}

For forming structural-mechanical properties of sour milk pastes and guaranteeing their stability at storage, it is promising to introduce cereals in recipe compositions [1]. Buckwheat is remarkable among cereals for rather high content of protein $-13,0 \ldots 15,0 \%$. The peculiarity of buckwheat proteins comparing with proteins of other cereals is practically complete absence of prolamins, low content of glutelin and high content of albumin and globulins [2]. Buckwheat protein contains 18 amino acids, grains are rich with arginine and lysine, biological value of proteins is $93,1 \%$ [3]. It is one of most full-value vegetable proteins, characterized by the high solubility and assimilability. Buckwheat proteins have a high moisture-keeping ability and emulsifying properties. These characteristics may be used for directed formation of the structure and increase of the food value of products [4].

Buckwheat starch granules [5,6] are mainly polygonal, less often spherical and oval, and particles surface - uneven that conditions it stabilizing and moisture-keeping properties.

The general content of buckwheat food fibers is $5 \ldots .11 \%$, among them - cellulose, nonstarch polysaccharides, lignans. Soluble cellulose prevails in buckwheat.

Food fibers and slime of buckwheat have a moisture-keeping ability. They can form chelate compounds with heavy metals and cholesterols, inhibit tumors formation, favor metabolism normalization [7].

\section{Materials and Methods}

Model samples of the sour milk base for pastes based on sour cream with fat mass share $20 \%$, acidity $80^{\circ} \mathrm{T}$ were prepared for the study. Previous studies established [8] that non-fried buckwheat is preliminary comminuted to the particles size no more than $2 \mathrm{~mm}$ that increases accessibility of components of the internal part of a grain. Comminuted buckwheat in the amount $5,0 \%$ was mixed with milk whey in ratio $1: 4$ and thermally processed at the temperature $(90 \pm 2)^{\circ} \mathrm{C}$ during $10 \ldots 15$ minutes. The prepared stabilizing component was introduced into the sour milk base at the temperature $(20 \pm 2){ }^{\circ} \mathrm{C}$ in the amount $25,0 \%$ of the mixture mass.

At more value of the hydro module the mixture consistence is liquid, excessive moisture is present. At the hydro module less than 1: 4 - the mixture consistence is dense and loses its fluidity.

The active acidity of buckwheat-whey mixture also changed depending on the buckwheat-milk whey ratio. At the hydromodule 1: 2 and 1: 3 the active acidity was 4,7 $\mathrm{pH}$ units, at the hydromodule 1: 4-4,5 pH units, and at the hydromodule 1: 6-4,3 $\mathrm{pH}$ units. The active acidity value is within limits, typical for sour milk pastes and the additional correction of buckwheat dose is not needed.

For substantiating technological parameters of buckwheat preparation, there was studied the influence of the temperature and duration of the process of buckwheat-whey mixture preparation on the moisture-keeping indicator. Based on obtained data, there was observed a proportional dependence, the higher temperature of mixture preparation, the better mixture ability to keep moisture is. The highest moisture-keeping indicator was observed at the temperature $85{ }^{\circ} \mathrm{C}-73,0 \%$, at further temperature rise this indicator increased by $1,0 \%$. In further it was decided to apply the temperature of buckwheat-whey mixture preparation $(90 \pm 2){ }^{\circ} \mathrm{C}$.

The moisture-keeping ability in a sample with the process duration 15 minutes was $76,0 \%$, whey mixture preparation $(90 \pm 2){ }^{\circ} \mathrm{C}$. The moisture-keeping ability in a sample with the process duration 20 minutes increased only by $0,1 \%$.

For the control, a sample was prepared using phosphate starch E-1410 as a moisture-keeping component that is characterized by the ability to form rather viscous pasters, tolerant to $\mathrm{pH}$ medium changes and mechanical effects, stable at storage. The preparation of the moisture-keeping component was realized as following. Milk whey, heated to the temperature $(40 \pm 2){ }^{\circ} \mathrm{C}$ was added with modified starch in the amount 5,0 \% at continuous mixing. The preparation of the starch-whey paster of a higher concentration is not expedient, because such solutions are characterized with a high viscosity and lose fluidity. The mixture was heated to the temperature $(82 \pm 2)^{\circ} \mathrm{C}$ and kept during $30 \mathrm{~s}$, after which cooled to $(20 \pm 2){ }^{\circ} \mathrm{C}$. The whey-starch paster was introduced in the sour milk base in the amount $25,0 \%$ of the mixture mass. The content of modified starch in a ready product was 
$1,3 \%$. Such doses of introduction of stabilizing components allow to get sour milk pastes with similar indicators of dynamic viscosity.

For studying the moisture content, the most informative method is dynamic thermogravimetry, because it allows to make measurements of the temperature of the studied sample (T), measurements of its mass (TG), speed of mass change (GTG), measurements of enthalpy (DTA) synchronously.

Thermogravimetry (TG) - it is a method of thermal analysis, at which a mass change depending on a temperature is registered. TG-curve gives information about thermostability and content of a sample in the initial condition, formed at intermediate stages of the process, and about the content of a residual, if it takes place. This method is effective, only if a sample emits volatile matters as a result of different physical and chemical processes [9].

Thermogravimetry by a derivative (GTG) - in this case a derivative of a mass change in time is registered:

$$
\frac{\mathrm{dm}}{\mathrm{dt}}
$$

as a function of a temperature or time, that is:

$$
\frac{\mathrm{dm}}{\mathrm{dT}}=\mathrm{f}(\mathrm{T})
$$

or

$$
\frac{\mathrm{dm}}{\mathrm{dt}}=\mathrm{f}(\mathrm{t})
$$

Differential-thermal analysis. The method of differential-thermal analysis DTA, (Fig. 1) is based on the comparison of properties of a sample (2) of the studied substance and thermally inert substance, taken as a standard (1). A registering parameter is a difference of their temperatures (3), measured at the cooling of a sample with a constant speed that can be presented as a functional dependence as a function of a temperature of a sample and standard. The change of a standard temperature is caused by physical transitions or chemical reactions, connected with enthalpy changes. They include: phase transitions, melting, reconstruction of the crystal structure, boiling, sublimation and evaporation, reactions of dehydration, dissociation and decomposition, oxidation and restoration, destruction of a crystal lattice and so on. These transformations are accompanied with absorption or emission of heat. In the general case phase transitions, dehydration, restorations and several reactions of decomposition are accompanied with endothermic effects, and crystallization, oxidation and several processes of decomposition - with exothermic effects.

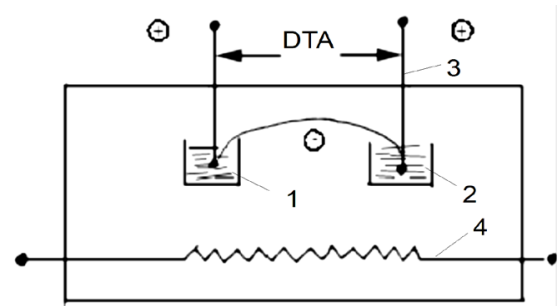

Fig. 1. Scheme of DTA method. 1 - crucible with a standard, 2 - crucible with a sample, 3 - differential thermocouple, 4 - heater

The study of the moisture condition was determined by the thermogravimetric method using a derivatograph Q-1500D (Fig. 2) (Paulik-Erdey), made in Hungry. 


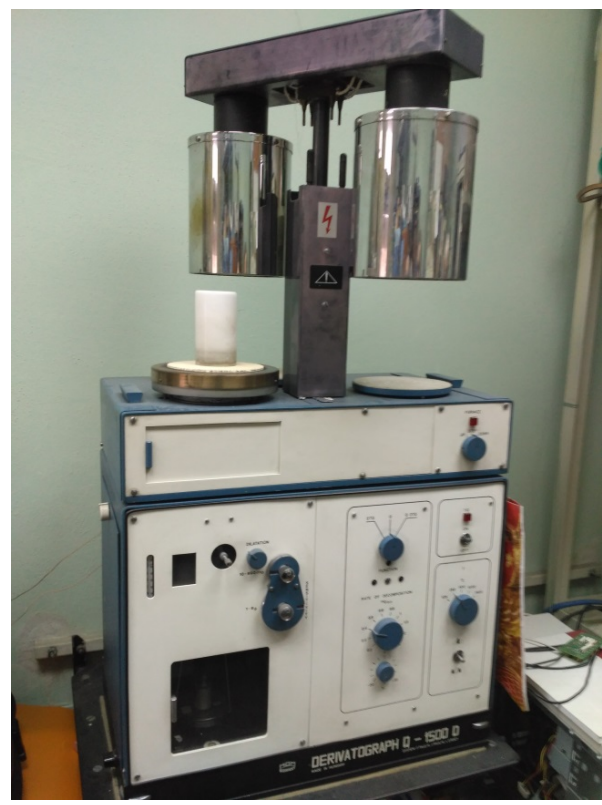

Fig. 2. Derivatograph Q-1500 D

The derivatograph is equipped with analytic thermoscales, the ceramic holder for samples and standard is fixed on one yoke of them. Three thermocouples are placed on the holder. Crucibles with samples can be placed on two thermocouples, a crucible with a standard - on the third one.

This device can function in two regimes: the regime of simple thermometry and the regime of differential thermometry. In the first case one simple thermocouple with a crucible with a sample is used in the work. In the second case a differential thermocouple, consisted of two simple thermocouples, connected to each other by homonymous poles, is used. A crucible with a sample is placed on one of them, on the other - with a standard substance. The choice of one of shooting regimes is realized by a switch, placed on the front panel of the device. Two devices, used for measuring a weight loss and a weight loss speed of a sample, are placed on the other yoke of scales. The principle of the work of these devices is based on magnetic induction.

The principal scheme of the derivatograph is presented on Fig. 3.

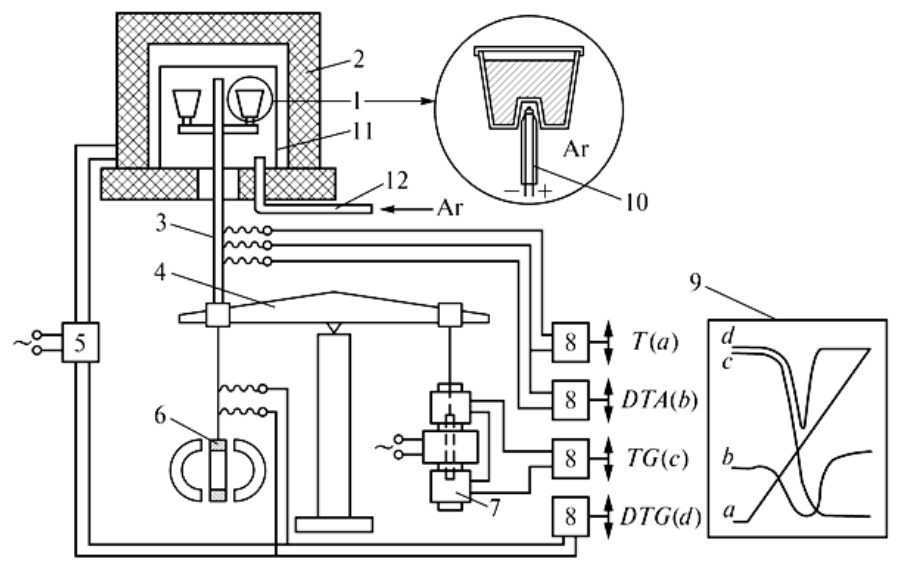

Fig. 3. Principal scheme of the derivatograph Q-1500D: 1 - crucible with the studied sample; 2 - stove; 3 - ceramic tube with thermocouples; 4 - scales; 5 - programmer of heating; 6 - sensor of a mass change speed; 7 - sensor of a mass change; 8 - output signal amplifier; 9 - derivatogram; 10 - thermocouple; 11 - protective quartz glass; 12 - feeder of inert gas; $a$ - temperature change of a standard $(T) ; b$ - record of differential analysis $(D T A)$; $c$-standard mass change $(T G) ; d$ - standard mass change speed $(D T G)$ 
For measuring a weight loss, there is used a differential transformer (7), consisted of three coils, placed vertically on the same axis. The transformer is fixed immovably on the device corpus. A metal core, suspended on the scale yoke, is placed inside of the transformer. This core moves when a mass of the studied sample changes. When alternating current is fed on the middle coil (primary winding of the transformer), inductive current appear in neighboring coils (secondary winding of the transformer), connected oppositely (differentially). At the symmetric position of a core, the summary tension on coils of the secondary winding of the transformer is practically equal to null. At the core displacement the summary tension changes proportionally to the displacement value. Thus, the differential transformer reforms the movement of a scale arm in an electric signal, fixed by the registering device. The high sensitivity and measurement distinctness are typical for the differential transformer.

GTG curve is formed by a sensor of a mass change (6), consisted of a permanent magnet and inductive coil. An inductive coil is suspended on scales and placed in the field of a permanent magnet. When a sample mass changes, a coil begins to move in the homogenous magnet field. At this movement inductive current, which value is proportional to a mass change speed, appears in coil loops. Signals from thermocouples, differential transformer and inductive coil are fed through an amplifier. Thus, we synchronously get curves of the simple (T) and differential thermal (DTA) analyzes, mass loss curve (TG) and mass loss speed curve GTG) on a computer monitor [10].

Methods of the calculation of kinetic parameters of dehydration processes, such as activation energy (E) and pre-exponential factor $\left(\mathrm{k}_{0}\right)$, are described in work [11]. The linear law of the temperature change is applied. The kinetic equation of desorption process can be signed as:

$$
\mathrm{d} \Theta / \mathrm{dt}=-\mathrm{k} \Theta \mathrm{n} ; \mathrm{k}=(-\mathrm{d} \Theta / \mathrm{dt}) / \Theta \mathrm{n}
$$

The water covering degree of biopolymer molecules $(\Theta)$ changes from 1 (filling with an initial material) to 0 (after complete evaporation of moisture from a material). The reaction order (n) - integral number from 1 to 3 , it is assumed that the covering degree of biopolymer molecules is known from the experiment. The constant of a reaction speed $(\mathrm{k})$, can be signed as:

$$
\mathrm{k}=\mathrm{k}_{0} \exp (-\mathrm{E} / \mathrm{RT})
$$

where $\mathrm{R}$ - the universal gas constant (assumed as a constant value).

Substituting equation (4) in equation (5) and finding a logarithm, we get:

$$
\ln \mathrm{k}=\ln [(-\mathrm{d} \Theta / \mathrm{dt}) / \Theta \mathrm{n}]=\ln \mathrm{k}_{0}-\mathrm{E} / \mathrm{RT}
$$

Assuming initial conditions $\Theta \mathrm{t}=0=1, \Theta \mathrm{t}=\infty=0$ and experiment at the constant heating speed $(\beta)$, that is the linear dependence of a temperature on time

$$
\mathrm{T}(\mathrm{t})=\mathrm{T}_{0}+\beta \mathrm{t}
$$

The following expressions can be signed:

$$
\Theta(\mathrm{t})=\mathrm{ST} / \mathrm{S}_{0} ;-\mathrm{d} \Theta / \mathrm{dt}=\beta \mathrm{f}_{3} / \mathrm{S}_{0},
$$

where $\mathrm{S}_{0}$ and $\mathrm{ST}$-correspondingly areas on the graph $\mathrm{f}_{3}$ in the whole peak and the part of the peak from $\mathrm{T}$ to $\infty$.

$$
S_{T}=\int_{T}^{\infty} f_{3} d T ; \quad S_{0}=\int_{0}^{\infty} f_{3} d T .
$$

If all assumptions, based in this method, are correct and an order of $\mathrm{n}$ reaction is chosen correctly, the dependence $\ln [(-\mathrm{d \Theta} / \mathrm{dt}) / \Theta \mathrm{n}]$ from the reverse temperature $(6)$ is linear on the whole 
temperature interval. Having experimental values of $f_{3}$ and $\beta$, by expressions (8) and (9), we get $\Theta$ and $\mathrm{d} \Theta / \mathrm{dt}$, parameters of anisothermic kinetics $\mathrm{k}_{0}$ and $\mathrm{E}$ are calculated from equation (6).

The advantage of the aforesaid procedure is the use of the whole massive of experimental data, including the high-temperature part of a thermogram that is especially important at determining $\mathrm{n}$ order, establishing the reaction mechanism and model adequacy.

\section{Results}

Based on the analysis of properties of cereals, there was grounded the choice of non-fried buckwheat as a structure-forming and enriching component $[5,6]$. There were established technological parameters of production of sour milk pastes with spices. There was grounded a perspective of using non-fried buckwheat in the composition of recipes of sour milk pastes as a structure stabilizer. There were determined non-fried buckwheat compatibility with a milk base by organoleptic parameters, established a recommended dose of its introduction $-5,0 \ldots 6,0 \%$ [8].

The dependences of TG, GTG and DTA for the sour milk paste, stabilized by modified starch and for the sour milk paste, stabilized by the buckwheat-whey mixture, were received during the study. Analyzing the dependences of the relative mass loss for the studied samples, we observe that the mass loss takes place at heating in the temperature interval $30-175^{\circ} \mathrm{C}$. It is accompanied by the peaks on GTG temperature dependences in the same temperature interval.

At heating the mass loss of samples is accompanied by the endothermic peaks on the temperature dependencies of DTA. An endothermic peak is connected with a phase transition of 1 kind - evaporation. The wide temperature interval $\left(30-175^{\circ} \mathrm{C}\right)$ may be connected with the fact that water is in different conditions in samples.

That is why we divided GTG dependence in three peaks with the maximums at the temperatures $\mathrm{T}_{1}=111^{\circ} \mathrm{C}, \mathrm{T}_{2}=116^{\circ} \mathrm{C}$ and $\mathrm{T}_{3}=130{ }^{\circ} \mathrm{C}$ using Gauss distribution.

The first peak $\left(f_{1}\right)$ is connected with evaporation of moisture of the physical-mechanical bond - capillary and butt one that is in rough macropores of a sample. The second and third ones $\left(f_{2}, f_{3}\right)-$ are connected with evaporation of moisture of the physical-chemical bond and moisture of polymolecular and monomolecular hydrate layers. Water in the hydrate tunic is bound with a biomolecule by hydrogenous bonds, broken at heating.

Table 1 presents the distribution of free and bound moisture in the studied samples. According to the results of the differential-thermal analysis, there were calculated activation energy (E) and pre-exponential factor $\left(\mathrm{k}_{0}\right)$ at the temperatures of the maximal removal of adsorptionally bound moisture.

It was established, that the content of adsorptionally bound moisture is at the same level for studied samples. For a studied sample - sour milk base with buckwheat the content of free (capillary bound) moisture is by 1,0\% more comparing with the sour milk base, structured by the traditional stabilizer (modified starch). It proves the expedience of using non-fried buckwheat as a moisture-binding component in the technology of sour milk pastes.

Table 1

Summary data of thermogravimetric indicators of sour milk pastes

\begin{tabular}{cccccc}
\hline Name of a studied sample & \multicolumn{3}{c}{$\begin{array}{c}\text { Distribution of values } \\
\text { of components, } \%\end{array}$} & $\begin{array}{c}\text { Pre-exponential } \\
\text { factor }\left(\mathbf{k}_{\mathbf{0}}\right)\end{array}$ & $\begin{array}{c}\text { Activation energy } \\
\text { (E) } \mathbf{k J} / \mathbf{m o l}\end{array}$ \\
\hline $\begin{array}{c}\text { Sour milk paste, stabilized by } \\
\text { modified starch }\end{array}$ & 52,5 & 34,5 & 13,0 & 110 & 363 \\
$\begin{array}{c}\mathbf{f}_{\mathbf{1}} \\
\begin{array}{c}\text { Sour milk paste, stabilized by } \\
\text { buckwheat-whey mixture }\end{array}\end{array}$ & 52,0 & 34,0 & 14,0 & 100 & 330
\end{tabular}

\section{Conclusions}

Based on the thermogravimetric analysis, there was realized the comparative analysis of the moisture condition in sour milk pastes with using non-fried buckwheat and modified starch. The 
content of adsorptive moisture of the sour milk paste with using non-fried buckwheat is 34,0\%, that is comparable with its content in a sample of the paste using modified starch $(34,5 \%)$.

The data prove the effectiveness of using buckwheat as a moisture-binding component in the amount $6,0 \%$ of a mixture mass.

Such properties of non-fried buckwheat may be explained by the presence of starch compounds and easily accessible protein in its composition, able to hydration in the process of preparation of a component and to keeping moisture at further storage of a product.

The obtained results will be a base for elaborating sour milk recipes on the base of sour cream using non-fried buckwheat as a structure-forming and moisture-keeping component.

\section{References}

[1] Glagoleva, L. E., Korneeva, O. S., Shuvaeva, G. P. (2012). Characterization of sorption properties of plant non-starch polysaccharide complexes. Chemistry of plant raw materials, 1, 215-216.

[2] Batlug, Y. (2013). Analiz of the everyday production of milk products with cereal napovnuvachami. Scientific search for young researchers, 2, 6-10.

[3] Grigorenko, O. (2013). Development of food products enriched with trace elements as a means of solving the problem of hyper and hypomicroelementosis. Vysnyk Don NUET, 1 (57), 33-41.

[4] Buckwheat is green. Available at: http:/grechka-zelenaya.ru/ogrechke-zelenoj/grechka-zelenaja-sport-syroedenie/grechka-zelenaja.html

[5] Ikeda, S., Kreft, I., Asami, Y., Mochida, N., Ikeda, K. (2008). Nutrition educational aspects on the utilization of some buckwheat foods Fagopyrum. Food Chem, 25, 57-64.

[6] Cao, W., Chen, W.-J., Suo, Z.-R., Yao, Y.-P. (2008). Protective effects of ethanolic extracts of buckwheat groats on DNA damage caused by hydroxyl radicals. Food Research International, 41 (9), 924-929. doi: 10.1016/j.foodres.2007.10.014

[7] Zhang, L., Li, Z. (2009). Functional Characteristics of Traditional buckwheat product. Journal of Chinese Cereals and Oils Association, 24 (3), 53-57.

[8] Pasichnyi, V., Yushchenko, N., Mykoliv, I., Kuzmyk U. (2015). Structure Stabilization of Fermented-Milk Pastes. Ukrainian Food Journal, 1, 402-410.

[9] Kovalov, K. M., Alekseev, O. M., Lazarenko, M. M., Zabashta, Y. F., Grabovskii, Y. E., Tkachov, S. Y. (2017). Influence of Water on the Structure and Dielectric Properties of the Microcrystalline and Nano-Cellulose. Nanoscale Research Letters, 12 (1), 468-473. doi: 10.1186/s11671-017-2231-5

[10] Prytulska, N., Fedorova, D., Lazarenko, M., Vasylieva, O., Yudina, T. (2016). Thermogravimetric research into fish and plant semifinished products made of raw and blanched tissues of Azov goby and wheat bran. Eastern-European Journal of Enterprise Technologies, 6 (11 (84)), 22-30. doi: 10.15587/17294061.2016.86435

[11] Pichkur, V., Lazarenko, M., Alekseev, O., Kovbasa, V., Lazarenko, M. (2015). Thermogravimetric research of the extruded and native types of starch. Eastern-European Journal of Enterprise Technologies, 1 (6 (73)), 52-56. doi: 10.15587/1729-4061.2015.33116 